\title{
Temporal dynamics, residency and site fidelity of spawning aggregations of a herbivorous tropical reef fish Siganus sutor
}

\author{
Jude P. Bijoux ${ }^{1, *}$, Laurent Dagorn ${ }^{1}$, Gregory Berke ${ }^{2}$, Paul D. Cowley ${ }^{3}$, Marc Soria ${ }^{4}$, \\ Jean-Claude Gaertner ${ }^{5}$, Jan Robinson ${ }^{2,6}$ \\ ${ }^{1}$ Institut de Recherche pour Développement (IRD), UMR 212, Victoria, Mahé, Seychelles \\ ${ }^{2}$ Seychelles Fishing Authority, Victoria, Mahé, Seychelles \\ ${ }^{3}$ South African Institute for Aquatic Biodiversity, Grahamstown 6140, South Africa \\ ${ }^{4}$ Institut de Recherche pour Développement (IRD), UMR 212, Saint Denis, La Réunion \\ ${ }^{5}$ UMR 241 EIO (UPF, IRD, Ifremer, ILM), Faaa, Tahiti, Polynésie Française \\ ${ }^{6}$ Australian Research Council Centre of Excellence for Coral Reef Studies, James Cook University, Townsville, \\ Queensland 4811, Australia
}

\begin{abstract}
The shoemaker spinefoot Siganus sutor is a fast-growing, short-lived, gonochorist and herbivorous reef fish that forms transient fish spawning aggregations (FSAs). In the Seychelles, FSAs of this species occur monthly between September and June around the full moon. To study the spawning aggregation dynamics of $S$. sutor, 39 reproductively active individuals were acoustically tagged and monitored at 3 known FSA sites (Paté Polite, Paté Désiré and Paté Dividi) off the west coast of Praslin island (Seychelles) between October 2010 and April 2011. The presence and absence of tagged fish at the 3 sites were monitored using moored arrays of passive acoustic receivers, while the density of fish at the FSAs was quantified using underwater visual census (UVC). Most tagged fish (87.0\%) detected in more than 1 spawning period showed fidelity to single spawning sites. Predominantly, tagged individuals arrived at FSA sites at dawn and departed at dusk. Spawning residency times at FSA sites ranged from 0.02 to $16.1 \mathrm{~d}$. At Paté Polite, residency times were higher in the first half of the spawning season. Residency times were often several-fold shorter than aggregation duration which, when combined with patterns in arrival and departure times, indicates high turnover of fish within aggregations. The findings of this study provide information needed for emerging co-management schemes that aim to sustain this socio-economically important fishery.
\end{abstract}

KEY WORDS: Fish spawning aggregation - Siganus sutor $\cdot$ Acoustic telemetry $\cdot$ Residency time Site fidelity $\cdot$ Seychelles

\section{INTRODUCTION}

The formation of spawning aggregations at predictable times and locations renders many reefassociated fishes vulnerable to overfishing (Sadovy \& Domeier 2005). Fish spawning aggregations (FSAs) are typically classified as either transient or resident.
Transient FSAs draw individuals to sites located outside of the typical home range areas of adults, whereas resident FSAs tend to form within or near adult home range areas of reef (Domeier \& Colin 1997, Domeier 2012). It has been suggested that species forming transient FSAs are more vulnerable to overfishing than those forming resident FSAs 
(Sadovy de Mitcheson \& Colin 2012) since transient FSAs are more predictable in time and space, persist for longer periods, involve greater proportions of the spawning stock biomass at each aggregation, and are common to larger species of high commercial value (Domeier \& Colin 1997). Furthermore, a single transient FSA may represent the total annual reproductive effort for participating individuals (Shapiro et al. 1993, Samoilys \& Squire 1994, Domeier \& Colin 1997). In certain parts of the world, transient FSAs have been fished to the point of collapse (Sala et al. 2001, Sadovy \& Domeier 2005, Aguilar-Perera 2006). The negative effects of exploiting spawning aggregations range from commercial extinction of the population to reduced reproductive output due to decreases in average fish size and altered sex ratios, particularly in protogynous species (i.e. those that change sex from female to male) such as certain groupers (Serranidae) (Sadovy 1996, Pears et al. 2006). It has been advocated that FSAs should not be exploited except in cases involving a subsistence level of use (Sadovy \& Domeier 2005), and measures to protect FSAs are now in place at several locations around the world (Aguilar-Perera \& Aguilar-Dávila 1996, Beets \& Friedlander 1999, Johannes et al. 1999).

Most behavioural studies of FSAs have focused on large, slow-growing, late-maturing, piscivorous, hermaphroditic species (Zeller 1998, Starr et al. 2007, Rhodes \& Tupper 2008, Rhodes et al. 2012). In contrast, the focus species of this study, the shoemaker spinefoot Siganus sutor, is a small (maximum standard length $=45 \mathrm{~cm}$ ), fast-growing, herbivorous, gonochoristic species that forms FSAs (Robinson et al. 2011). It is a member of 1 of the only 3 marine fish families (Balistidae, Pomacentridae and Siganidae) known to form spawning aggregations that have demersal eggs (Choat 2012). S. sutor is endemic to the western Indian Ocean (Woodland 1990) and is a commercially important target species in much of the region (Grandcourt \& Cesar 2003, Kaunda-Arara et al. 2003), often constituting more than $40 \%$ of inshore reef fishery catch by weight (Kamukuru 2009, Hicks \& McClanahan 2012). The locations and timing of several $S$. sutor FSAs are known to fishers in the region (Robinson et al. 2004) and some sites have been targeted since the early 1900s (Hornell 1927).

Information on spawning aggregation dynamics is essential for managing fisheries with important aggregation components, particularly in terms of assessing the effects of spatial and temporal management measures, such as reserves and seasonal effort or catch restrictions. Acoustic telemetry constitutes a powerful tool for studying FSA dynamics as it allows the presence and absence of tagged fish to be recorded for extended periods using fixed passive receiver arrays or their movement to be actively detected and tracked using mobile receivers. Consequently, the use of this technology for studying the dynamics of FSAs is increasing (Robichaud \& Rose 2003, Starr et al. 2007, Rhodes \& Tupper 2008, Semmens et al. 2010, Rhodes et al. 2012).

In this study, we applied passive acoustic telemetry and underwater visual census methods at 3 sites around the island of Praslin (Seychelles), where a fishery targeting Siganus sutor spawning aggregations has existed for almost a century (Hornell 1927). Within the greater Seychelles archipelago over the last few decades, a small percentage (approximately $15 \%$ ) of the annual catch of S. sutor has been taken at FSAs and trends in yield indicate that siganid resources in general have been fished within sustainable limits (Robinson et al. 2011). However, a precautionary approach has been recommended to an ongoing co-management initiative for this fishery, including gear-based controls and capacity/effort limitations (Robinson et al. 2011). In an emerging management context that may involve input controls and technical measures applied spatially and temporally, this study aimed to improve understanding of $S$. sutor spawning aggregation dynamics. Furthermore, as little is known about the spawning aggregation dynamics of small herbivorous species, this study will contribute towards a more comprehensive understanding of reproductive behaviour in reef fishes. The specific objectives were to (1) characterise the residency time of $S$. sutor at known FSA sites, (2) describe the lunar and diel pattern of arrival and departure at FSAs, (3) determine fidelity to specific spawning sites using acoustic telemetry, and (4) confirm aggregation formation based on $S$. sutor density estimates derived from underwater visual census, in order to interpret patterns in the acoustic data and to extend current knowledge of spatial and temporal patterns in aggregation formation.

\section{MATERIALS AND METHODS}

\section{Study area and receiver array}

An array of eighteen $69 \mathrm{kHz}$ VR2 and VR2W acoustic receivers (Amirix Systems) was deployed at 3 known Siganus sutor spawning aggregation sites off the west coast of Praslin Island, Seychelles 
(Fig. 1). The acoustic receivers were installed between 15 and 19 October 2010 and retrieved between 16 and 20 April 2011, giving a 6 mo deployment across a large portion of the known spawning season of September to June (Robinson et al. 2011). Six receivers were deployed at each of the 3 FSA sites of Paté Polite, Paté Désiré and Paté Dividi, hereafter referred to as Polite, Désiré and Dividi. Each site was mapped using a SIS-1624 dual frequency side scan sonar (Benthos) towed behind a $20 \mathrm{~m}$ research vessel (RV 'L'Amitié'). The profile, reef rugosity and horizontal area (size) of the 3 FSA sites varied substantially. Polite was the largest with a horizontal area of $70000 \mathrm{~m}^{2}$ followed by Dividi $\left(16000 \mathrm{~m}^{2}\right)$ and Désiré $\left(2900 \mathrm{~m}^{2}\right)$. While Dividi was made up of a large single patch reef, Désiré had 3 patch reefs surrounded by small sandy channels and Polite consisted of many patch reefs of different sizes. Despite the differences in size and number of patch reefs of the 3 FSA sites, they were all fully submerged granite patch reefs surrounded by sandy areas with their base at about $20 \mathrm{~m}$ and a minimum depth of about $15 \mathrm{~m}$. All sites had substantial (>60\%) hard coral cover. The acoustic receivers were secured to the bottom on concrete blocks (+40 kg), which were strategically positioned on and around the patch reefs on the recommendation of local fishermen to ensure maximum probability of detecting tagged fish. The recommendations for positioning of receivers by local fishermen were based on locations where they had previously observed concentration of S. sutor FSAs. Consequently, the spacing between receivers and array configurations differed at each site (Fig. 1). The minimum, maximum and mean spacing between receivers in the multiple site array were 17, 360 and $100 \mathrm{~m}$, respectively.

Acoustic range reception (range testing) using a sample acoustic receiver (VR2W) and tag (V8-4HS256, $69 \mathrm{kHz}, 110$ to $250 \mathrm{~s}$ delay) (Amirix Systems) was conducted at 1 of the FSA sites (Désiré) during daylight hours. The acoustic receiver was tied with the sensor facing upwards on a line that was

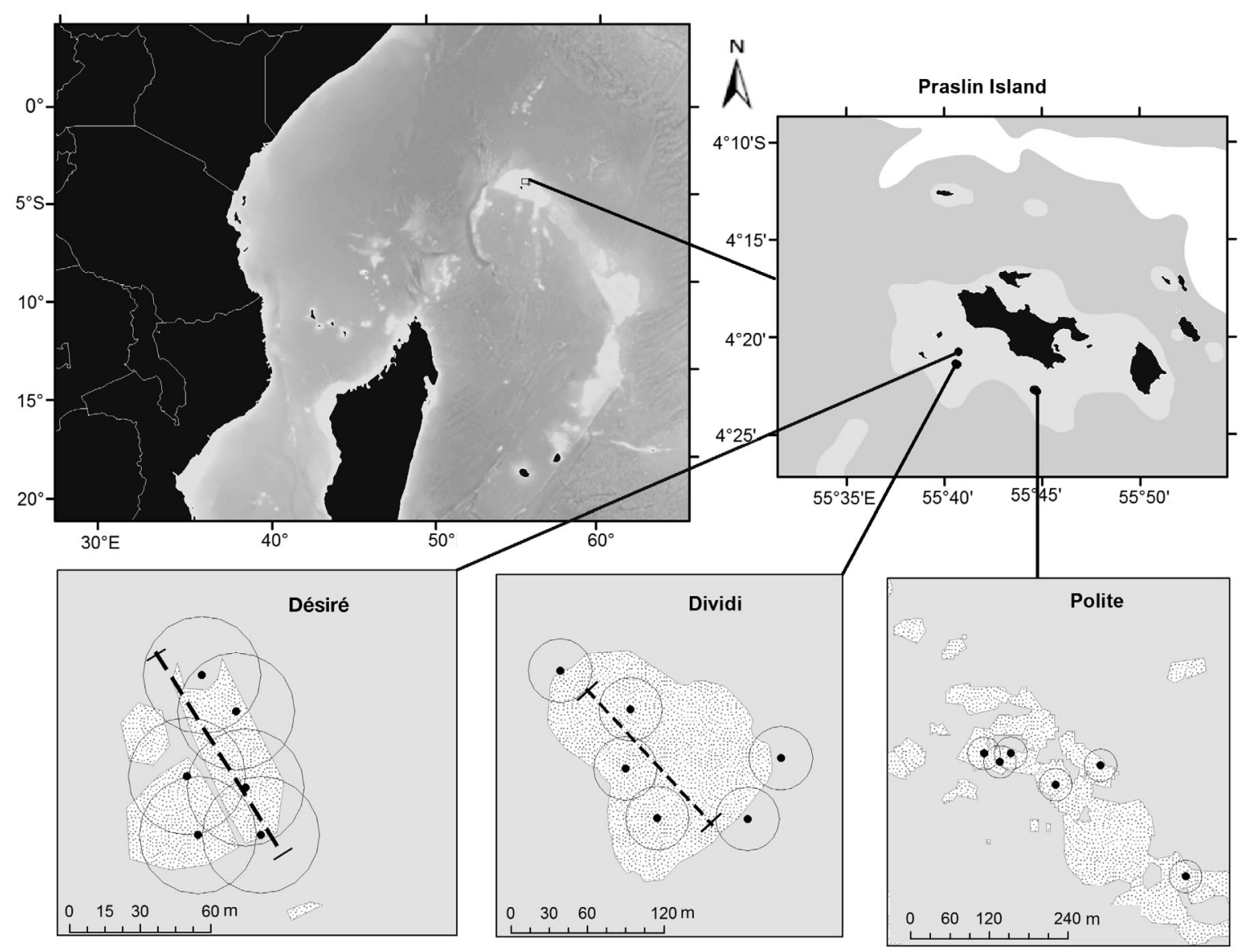

Fig. 1. Location of the study sites off the West coast of Praslin island, Seychelles. The dotted areas represent granite patch reefs and grey areas sand. The black dots on the 3 lower panels show the location of the acoustic receivers and the circle around each dot is the $25 \mathrm{~m}$ reception range of the receivers. The dotted lines show the location of transects used in the underwater visual census 
anchored on the edge of the site using lead weights with the other end tied to a plastic sea surface buoy. The sensor of the acoustic receiver was $3 \mathrm{~m}$ above the reef surface. The line from the anchor to the receiver was kept taut and approximately vertical by tying a small subsurface float $1 \mathrm{~m}$ above the receiver. A line to deploy the tag was prepared in the same way, with the tag also positioned on the line $3 \mathrm{~m}$ above the substratum. Range testing was done by placing the tag line at $0,25,50,100$ and $200 \mathrm{~m}$ distances from the receiver. At each distance, the tag was deployed in the water for $30 \mathrm{~min}$. The number of detections at $0 \mathrm{~m}$ was used as the baseline to compare the number of detections obtained at other distances. The detection level was $70 \%$ at $25 \mathrm{~m}$, but detections declined to nil at $50 \mathrm{~m}$ and beyond.

\section{Fish tagging}

Fish $(\mathrm{n}=39)$ were tagged between 20 and 22 October 2010 (at the start of the spawning aggregation season) and 19 and 21 January 2011 (during the middle of the spawning aggregation season). Fish were caught in spawning aggregations at the study sites by local fishermen using traditional bamboo traps with a 1 to $2 \mathrm{~h}$ soak time. To reduce barotrauma, traps were hauled slowly to the surface, where fish were immediately transferred to a holding tank. Fish were then transported to an aerated holding tank on a larger ship, where they were allowed to acclimatise for at least $30 \mathrm{~min}$ prior to tagging. Fish were anaesthetised by placing them in a continuously aerated 301 container filled with a $30 \mathrm{mg} \mathrm{l}^{-1}$ seawater/ benzocaine solution. Opercula and fin movements were monitored and recorded. After $5 \mathrm{~min}$, fish were removed, measured and double tagged using uniquely numbered T-bar tags (Floy Tag and Mfg) inserted at the 4 th dorsal pterygiophore. Fish were then transferred to a small, continuously aerated aquarium and placed dorso-ventrally to enable continual submergence of the gills. A V8-4H-S256 $(69 \mathrm{kHz}, 110$ to 250 s delay, $93 \mathrm{~d}$ battery life, $2 \mathrm{~g}$ in air, $<1 \%$ weight of smallest tagged fish) acoustic tag, sterilised in absolute ethanol, was then inserted in the body cavity through a small incision $2 \mathrm{~cm}$ anterior of the anus and below the lateral line. The incision was then closed using 2 non-absorbable polynylon sutures. At the end of the surgical procedure, fish were transferred into a recovery tank and monitored until normal colour and behaviour returned. Fish were released in small groups at the point of capture within $3 \mathrm{~h}$ of the trap being hauled.
Following the tagging of 2 groups of fish, at the start and middle of the spawning aggregation season, the study comprised 2 distinct monitoring periods (Period 1: October 2010 to January 2011; Period 2: January to April 2011). During monitoring Period 1, 10 fish were tagged and released at the Polite FSA and 9 at the Désiré FSA. During monitoring Period 2, 11 fish were tagged and released at the Polite FSA and 9 at the Dividi FSA. Tagged fish measured between 22.6 and $29.7 \mathrm{~cm}$ fork length and were considered sexually mature, based on the reported size at first maturity for this population (Robinson et al. 2011).

\section{Underwater visual census}

In order to obtain Siganus sutor density estimates, an underwater visual census (UVC) was undertaken at Dividi and Désiré in 5 different months (all within the second half of the spawning season) in 2010 and 2011. As $S$. sutor FSAs can start forming as early as $3 \mathrm{~d}$ before the full moon and last up to $3 \mathrm{~d}$ after the full moon (Robinson et al. 2011), each monthly survey was conducted over $7 \mathrm{~d}$, starting $3 \mathrm{~d}$ before the full moon and ending $3 \mathrm{~d}$ after it. In the event that a FSA was still at the site $3 \mathrm{~d}$ after the full moon, the census continued until the FSA dispersed. During each survey, a single diver (J. P. Bijoux) counted the number of $S$. sutor $5 \mathrm{~m}$ in front of him in a $10 \mathrm{~m}$ wide belt transect running the approximate length of the site $(125 \mathrm{~m}$ at Dividi and $100 \mathrm{~m}$ at Désiré). Horizontal visibility was always greater than $15 \mathrm{~m}$ during all surveys and is unlikely to have biased counts. The same transect areas, identified by a permanent weighted rope, were surveyed each time. Fish that entered the transect area within the diver's view after the counts had started were ignored. Counts were performed twice per day (separated by a 5 min delay) at each site to provide a mean daily density estimate and were expressed as number $\mathrm{m}^{-2}$. All censuses were carried out in the morning between 08:30 and 11:30 h.

\section{Data analyses}

Before the start of the analyses, all data files downloaded from the acoustic receivers were screened for false detections (foreign identification codes) caused by code collisions (Heupel et al. 2006). Tagged fish that were detected only within $6 \mathrm{~h}$ after being tagged and released $(n=4)$ were excluded along with all of their detections to remove those fish that were only 
transiting through the spawning aggregation sites at the time of being caught and not actively participating in the spawning aggregations. The resultant detections from the 35 fish retained were used in data analyses. Residency time was calculated based on the methods of Ohta \& Kakuma (2005) and was defined as the duration that an acoustically tagged fish was continuously detected by the acoustic array at 1 FSA site without day-scale ( $>24 \mathrm{~h}$ ) absences. If total residency time at a single FSA site represented more than $75 \%$ of the estimated tag battery life, the fish was considered to be resident at that site and was subsequently removed from all further analyses as it was not possible to distinguish between spawning and non-spawning related behaviour. Both truncated and non-truncated spawning residency times were used in the calculation of mean residency time at the FSA sites, as results from the plotting of survival curves (see Fig. A1 in Appendix) and the Wald statistic of the Cox proportional hazards regression model (Cox 1972) showed that the 2 types of residency times were not significantly different from each other $(\mathrm{p}=0.29$, $\mathrm{df}=1)$. The Cox proportional hazards regression model is a method used to investigate the effect of 1 or several variables on the time that a specified event takes place. In our case, the event is length of stay at the FSA sites. A significant difference between truncated and non-truncated residency times would indicate that the time that fish were tagged after their arrival at the FSA sites, the tagging process or a combination of the 2 factors could have significantly modified the observed lengths of stay at these sites. This method is frequently used to compare residency times of fish at specific locations (Govinden et al. 2012, Robert et al. 2012). Here, we define truncated residency times as those for which one end (at the start in our case) has been artificially shortened due to the unknown time of arrival of the fish at a FSA site before it was caught and tagged. Spawning residency times are defined as residency times which occurred, at least partially, within the $7 \mathrm{~d}$ spawning aggregation period described by Robinson et al. (2011), comprising $3 \mathrm{~d}$ before the full moon, the day of the full moon and $3 \mathrm{~d}$ after, and which accounts for inter-monthly variation in formation, duration and dispersal of aggregations. Fidelity to a single FSA site or use of multiple FSA sites over the spawning aggregation season was based on the detection of tagged fish at the FSA sites only within the $7 \mathrm{~d}$ spawning aggregation period. Due to the unavoidable constraint of using small tags with a maximum battery life less than the known duration of reproductive activity (approximately
$10 \mathrm{mo})$, fidelity to FSA sites could only be assessed for the active life of the tag (i.e. $93 \mathrm{~d}$ ).

The temporal dynamics of FSAs were assessed in relation to 2 rhythmic cycles, namely lunar and diel $(n=54)$. Residency times starting on the day of tagging were excluded from the analyses as they did not provide data on the arrival time of tagged fish at the FSA sites. Both cycles were analysed by means of circular statistics (Batschelet 1981) using the Oriana 4 software (Kovach Computing Services). Lunar and diel timing of arrivals and departures of tagged fish at FSA sites were converted to the degree of deviation from 0 with $1 \mathrm{~h}$ and 1 lunar day represented by angles of $15^{\circ}$ and $12.19^{\circ}$ respectively. The mean departure and arrival angles were used to calculate mean lunar and diel arrival and departure times. The Rayleigh test of randomness was used to test whether lunar and diel arrival and departure angles at the FSA sites were significantly different from random $(\alpha=0.05)$.

\section{RESULTS}

\section{Acoustic telemetry array detections}

After removal of false detections and detections of fish that were detected only within the $6 \mathrm{~h}$ after being tagged and released, the arrays at the 3 FSA sites yielded a total of 20213 detections. The number of analysed detections varied considerably between individuals, ranging from 5 to 3894 (mean \pm SD: $578 \pm$ 893). Detections were highest during the day (Fig. 2) and gradually increased from dawn until around dusk, after which time the number of detections abruptly decreased and remained low throughout the night. At Polite and Dividi, tagged fish were detected mostly during the full moon-centred spawning aggregation periods, as opposed to Désiré where they were detected throughout the month (Fig. 3). The number of detections that were recorded during the spawning aggregation periods comprised $64.3 \%$ of all detections made. Detections outside the spawning aggregation periods were mostly made at Désiré $(91.0 \%)$ and Polite $(9.0 \%)$ with only 1 detection recorded at Dividi.

\section{Lunar timing of arrivals and departures}

Circular analyses showed periodicity, coinciding with the full moon, in the lunar timing of arrivals and departures of tagged Siganus sutor at Polite and 
Dividi but not at Désiré (Fig. 4). There was a tendency for fish to arrive $0.9 \mathrm{~d}$ before and $0.5 \mathrm{~d}$ after the full moon at Polite and Dividi, respectively. At Polite, the first $3 \mathrm{~d}$ of the spawning aggregation period

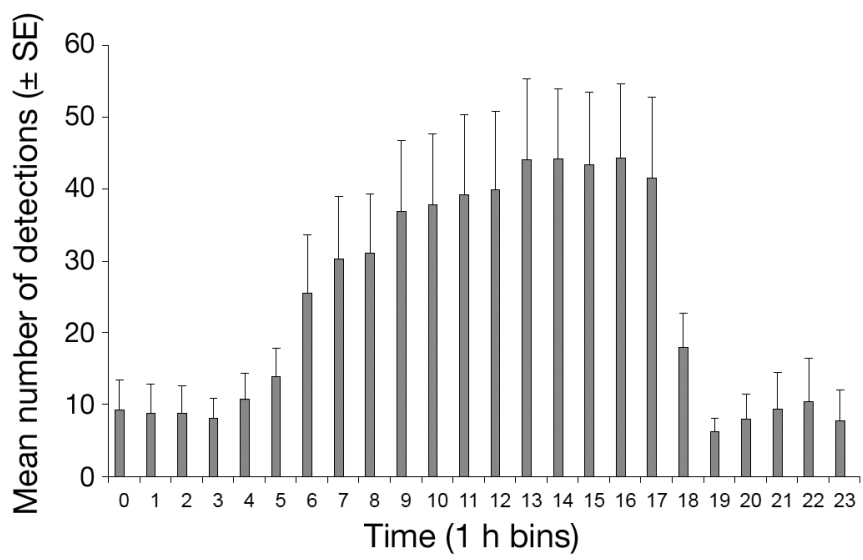

Fig. 2. Siganus sutor. Diel variation in the number of acoustic detections recorded at the 3 spawning aggregation sites (Dividi, Désiré and Polite) between 20 October 2010 and 16 April 2011. $\mathrm{n}=35$ fish, time bin 0 corresponds to 00:00 to $00: 59 \mathrm{~h}$ accounted for $68.0 \%$ of arrivals (Fig. $4 \mathrm{a}$ ), with a peak in daily arrivals (28.0\%) occurring $2 \mathrm{~d}$ before the full moon. At Dividi, $72.2 \%$ of arrivals occurred between the day of and $2 \mathrm{~d}$ after the full moon (Fig. 4b), with a peak in daily arrivals (33.3\%) occurring $2 \mathrm{~d}$ after the full moon. At both Polite and Dividi, no arrivals were detected outside the $7 \mathrm{~d}$ spawning aggregation period. Conversely, arrivals at Désiré occurred throughout much of the lunar month, with only $27.3 \%$ of arrivals occurring within the spawning aggregation period (Fig. 4c). Nevertheless, a peak in daily arrivals (18.2\%) at Désiré occurred $1 \mathrm{~d}$ after the full moon within the spawning aggregation period.

Mean departure of tagged fish took place 0.4 and $1.3 \mathrm{~d}$ after the full moon at Polite and Dividi respectively. At Polite, $56.0 \%$ of departures happened on the day of the full moon or earlier with a peak in departure $(24.0 \%)$ occurring $2 \mathrm{~d}$ before the full moon (Fig. 4d). While the majority of departures from Polite $(92.0 \%)$ took place within the monthly $7 \mathrm{~d}$ spawning aggregation period, there were a few departures $(8.0 \%)$ that occurred outside this period. All departures from Dividi occurred within a $6 \mathrm{~d}$ period start-

a

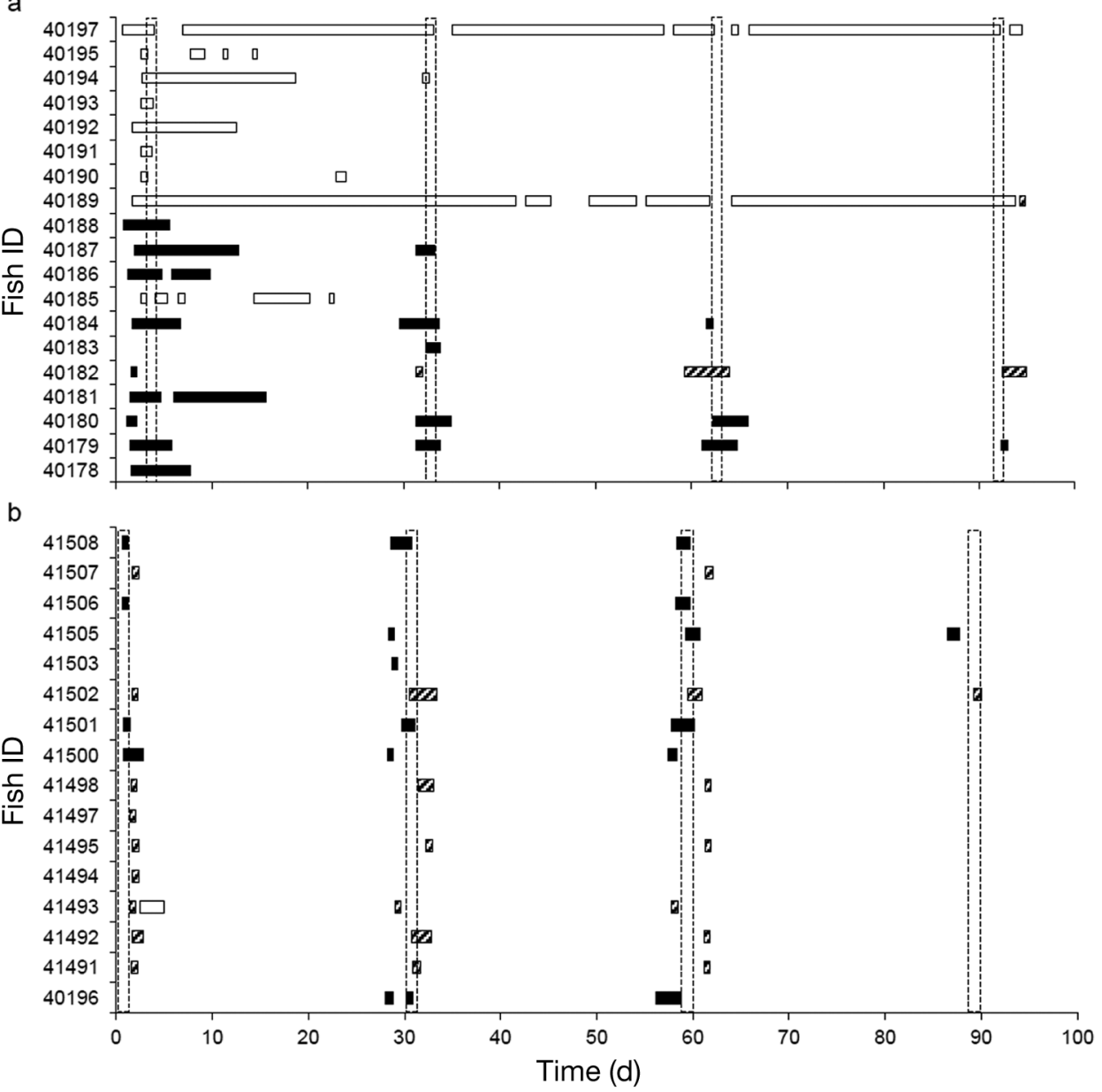

Fig. 3. Siganus sutor. Presence and absence of acoustically tagged fish at the 3 spawning aggregation sites during (a) monitoring Period 1 (October 2010 to January 2011) and (b) monitoring Period 2 (January to April 2011). Polite (black), Désiré (white) and Dividi (hatched). The vertical bars with dashed borders represent the days of the full moon 
a

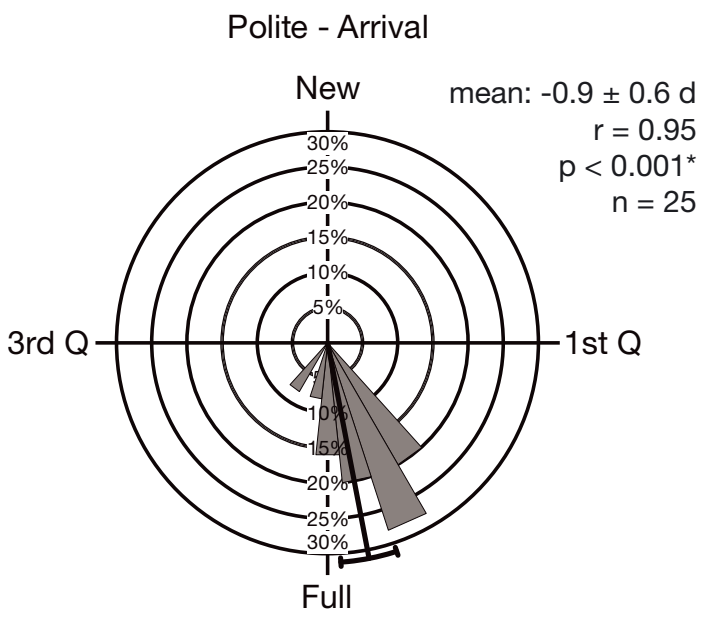

b

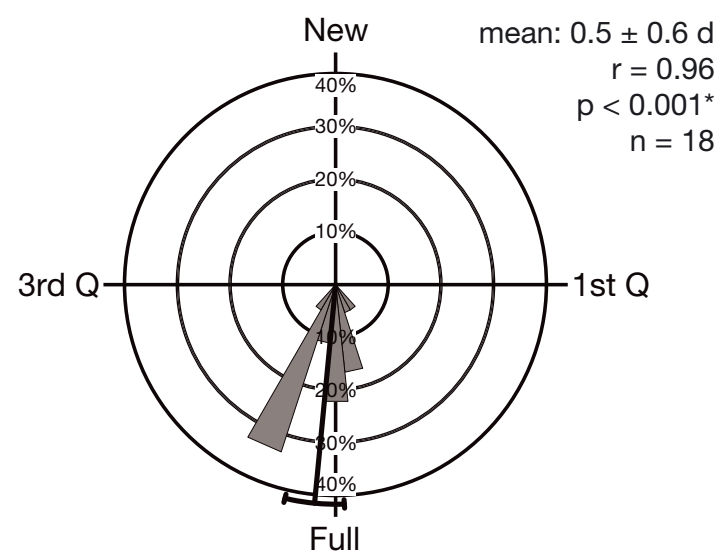

C

Désiré - Arrival

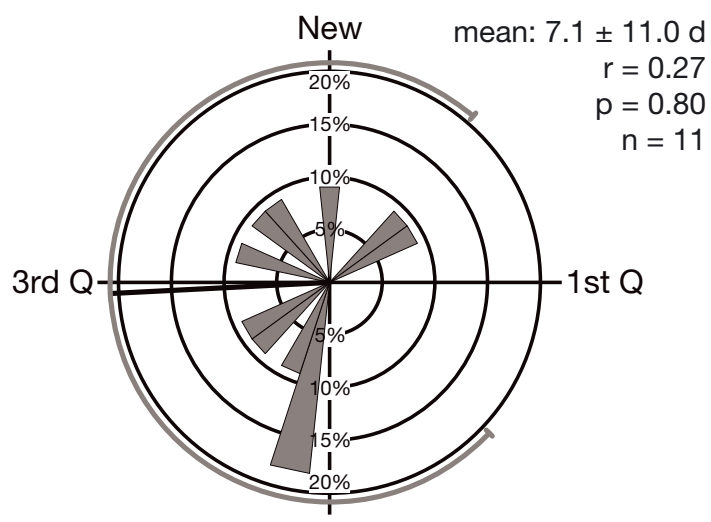

Full d

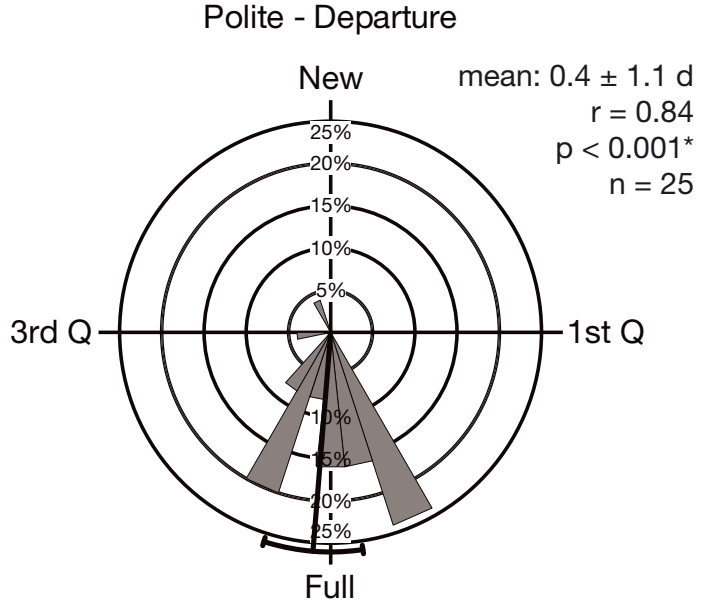

e

Dividi - Departure

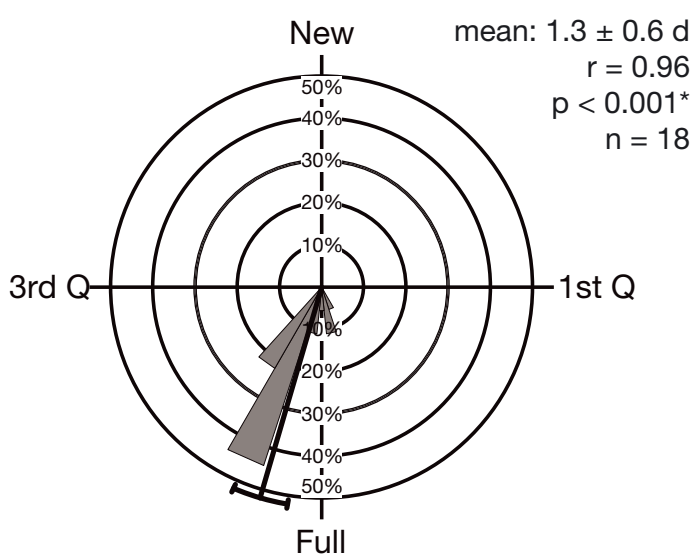

f

Désiré - Departure

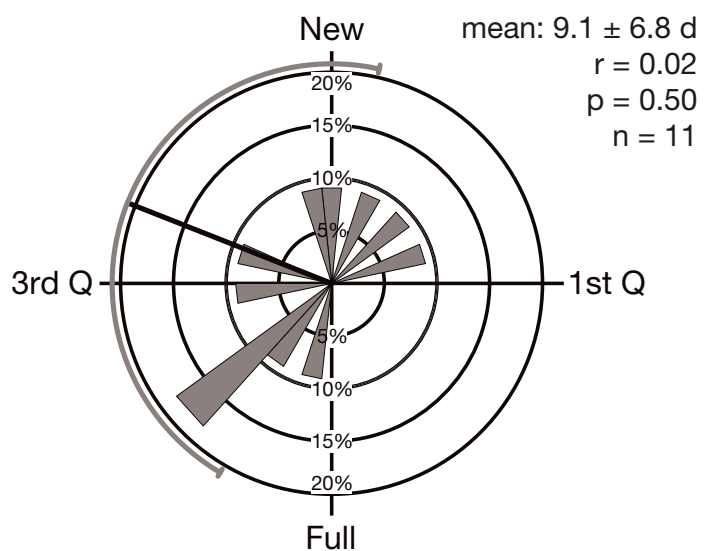

Fig. 4. Siganus sutor. Percentage of lunar arrivals of acoustically tagged fish at (a) Polite, (b) Dividi and (c) Désiré, and percentage of lunar departures at (d) Polite, (e) Dividi and (f) Désiré in relation to the lunar cycle. Mean arrival and departure day in relation to the full moon ( $\pm 95 \%$ confidence interval $[\mathrm{CI}]$ ) are superimposed. Grey error bars indicate unreliable CI due to low sample number or high spread of data. Q: lunar quarter; r: length of mean vector; n: number of samples; p: probability of data being randomly distributed (Rayleigh test of randomness: $\alpha=0.05)_{i}{ }^{*}$ indicates significant difference 
ing $2 \mathrm{~d}$ before and lasting until $3 \mathrm{~d}$ after the full moon (Fig. 4e), with the majority of departures (77.8\%) taking place after the day of the full moon. Similar to the pattern in lunar arrivals observed at Désiré, departures from this site occurred throughout most of the lunar month, except the period between the first quarter and the full moon (Fig. 4f).

\section{Diel timing of arrivals and departures}

Diel periodicity in the time of arrivals and departures of tagged Siganus sutor was found at Polite and Dividi, but once again not at Désiré (Fig. 5). At both Polite and Dividi, peaks in diel arrivals and departures coincided with the dawn and dusk periods, respectively. The hours between 05:00 and 10:00 h accounted for $56.0 \%$ of diel arrivals of tagged fish at Polite (Fig. 5a), with a peak in hourly arrivals (24.0\%) occurring between 06:00 and 07:00 h. At Dividi, the majority $(72.2 \%)$ of diel arrivals occurred between 05:00 and 07:00 h (Fig. 5b), with the other arrivals occurring at night between 18:00 and 04:00 h. All diel arrivals at Désiré occurred between 17:00 and 06:00 h (Fig. 5c), with 2 small peaks in hourly arrivals occurring between 05:00 and 06:00 $\mathrm{h}$ and between 17:00 and 19:00 h.

The majority (80.0\%) of departures from Polite took place between 17:00 and 19:00 h (Fig. 5d). All other departures from this site occurred during daylight hours between 06:00 and 16:00 h, but no hourly period accounted for more than $4.0 \%$ of departures. Similar trends in the diel timing of departures were observed at Dividi, where $66.7 \%$ of departures occurred between 17:00 and 19:00 h (Fig. 5e). Though there was no significant trend in diel periodicity of departures from Désiré, most departures (90.1\%) occurred at night between 17:00 and 06:00 h (Fig. 5f), with a peak $(27.3 \%)$ in departures occurring between 19:00 and 20:00 h.

\section{Spawning residency times}

Spawning residency times of tagged Siganus sutor at the 3 FSA sites ranged between 0.02 and $16.1 \mathrm{~d}$. Mean residency time $( \pm \mathrm{SD})$ during monitoring Period 1 was $3.0( \pm 5.3)$ and $3.7( \pm 2.8) \mathrm{d}$ at Désiré and Polite, respectively. During monitoring Period 2, residency times were lower, averaging $0.7( \pm 0.7)$ and $1.1( \pm 0.8) \mathrm{d}$ for Dividi and Polite, respectively. Residency times at Polite, the only site in which aggregating fish were tagged in both periods, de- clined significantly (Mann-Whitney $U$-test, $Z=-3.6$, $\mathrm{p}<0.001$ ) and were 3.3-fold lower in the second monitoring period.

\section{Spawning site fidelity}

Due to battery life, inferences relating to site fidelity were constrained to the 4 mo period in which the acoustic tags were active, which is equivalent to 4 spawning aggregation periods and approximately half of the spawning season. Of the 35 tagged fish analysed, $22(62.9 \%)$ were detected in more than 1 spawning period, while 13 were detected in only 1 (Fig. 6). The fish that were detected in more than 1 spawning period exhibited a high but not absolute degree of site fidelity, with 19 of the 22 fish $(86.4 \%)$ detected at only 1 monitored FSA site. Ten and 4 tagged fish visited the same FSA site on 3 and 4 consecutive spawning aggregation periods, respectively, whereas 5 others visited the same site twice. Two fish tagged in monitoring Period 1 (ID 40182, 40189) and 1 fish (ID 41493) tagged in monitoring Period 2 were detected at more than 1 FSA site (Fig. 3a,b). Fish ID 40182 was tagged at Polite in October 2010 and was subsequently detected at Dividi (more than $8 \mathrm{~km}$ away) over the next 3 spawning aggregation periods. Fish ID 40189 remained at the site of tagging (Désiré) for an extensive period ( $3 \mathrm{mo}$ ), including 6 consecutive days of the $7 \mathrm{~d}$ spawning aggregation period in the last month (January 2011) of monitoring Period 1. After departing Désiré at dusk on the 6th day of the spawning aggregation period (i.e. $2 \mathrm{~d}$ after the full moon), the same individual was detected the next morning at Dividi, where it stayed for $6 \mathrm{~h}$ and attended the spawning aggregation at that site with other tagged fish, further demonstrating the spatial and temporal scales of mobility. An individual (ID 41493) tagged at Dividi in January 2011 appeared at Désiré the day after tagging, where it stayed for $2.5 \mathrm{~d}$, and returned to Dividi during the 2 subsequent spawning aggregation periods of February and March 2011.

\section{Verification of aggregation formation}

UVCs conducted over 5 spawning aggregation periods at 2 sites (Dividi and Désiré) confirmed aggregation formation at Dividi in January and March 2011, and at Désiré in February 2010 (Fig. 7). The maximum average daily densities of Siganus sutor at Dividi in January $\left(2.4 \pm 0.1 \mathrm{~m}^{-2}\right)$ and March 
a

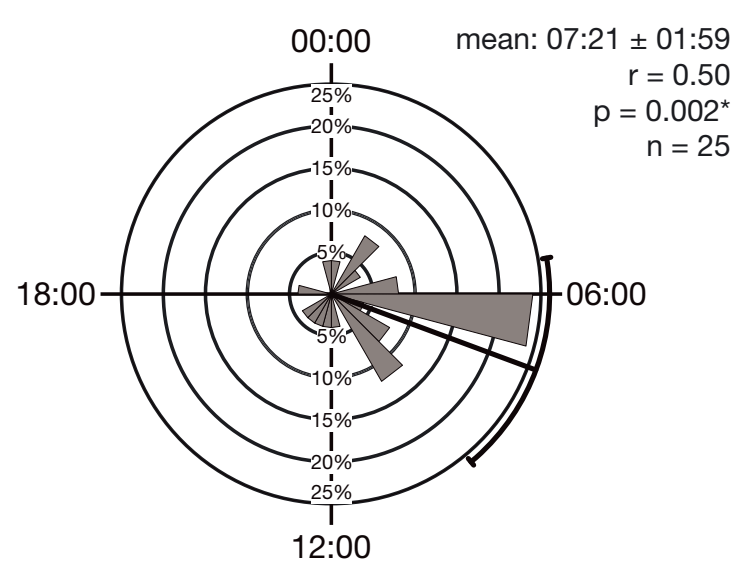

b

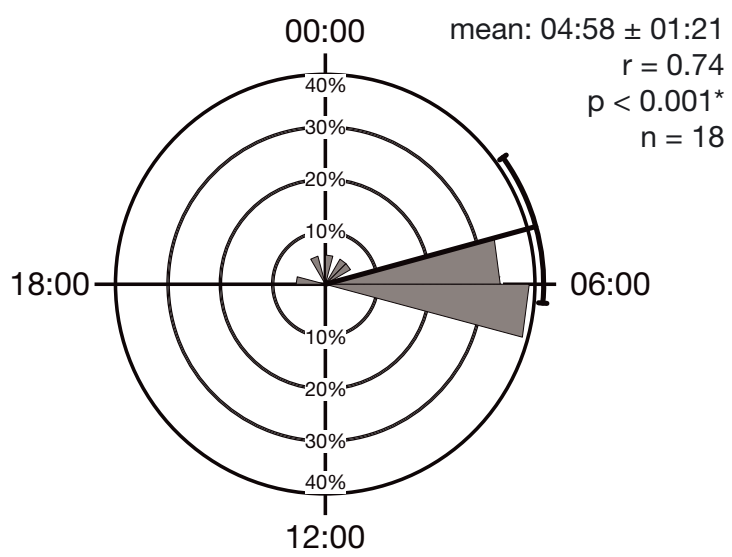

d

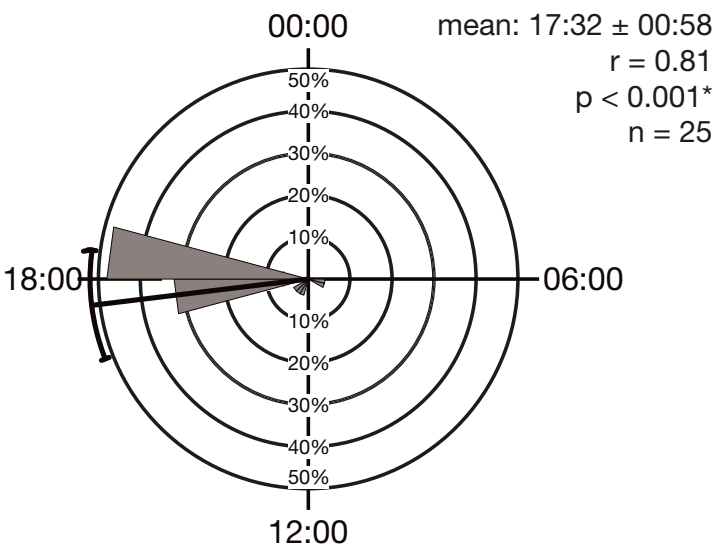

e

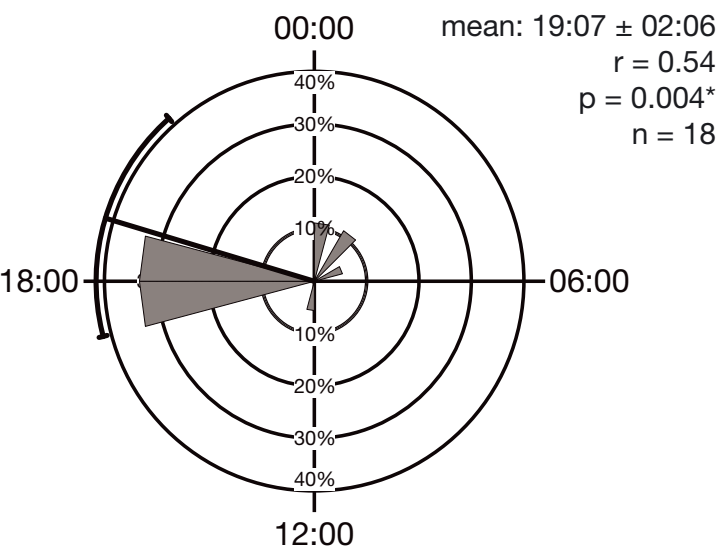

C

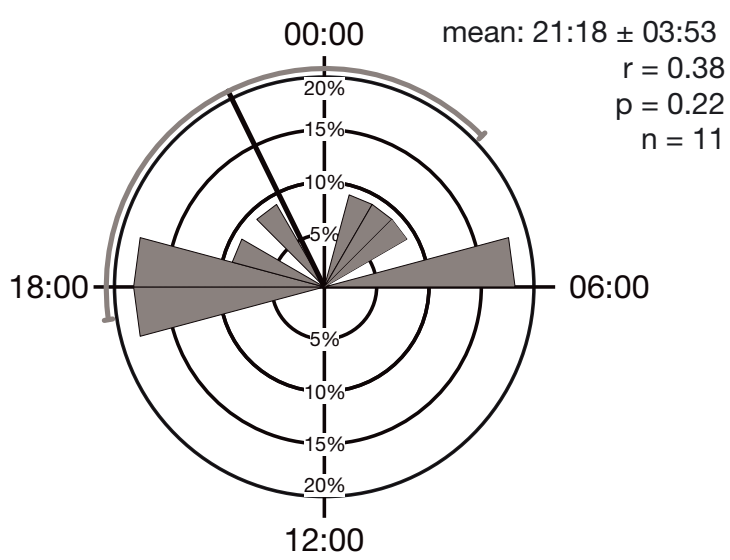

f

Désiré - departure

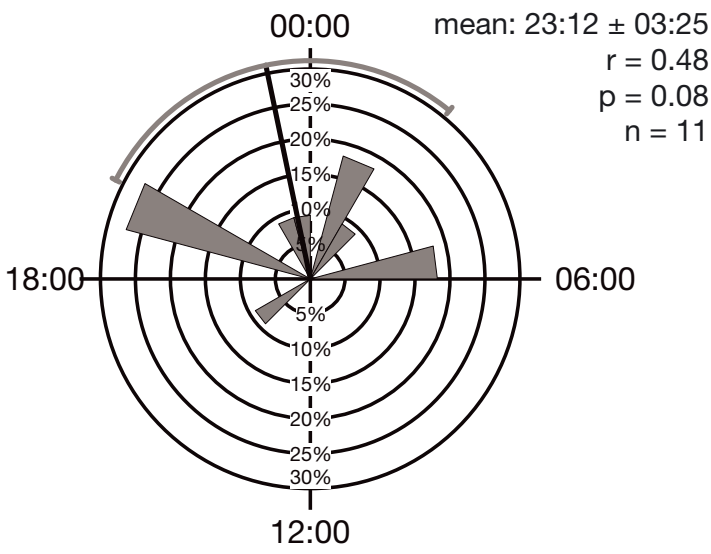

Fig. 5. Siganus sutor. Percentage of diel arrivals of acoustically tagged fish at (a) Polite, (b) Dividi and (c) Désiré, and percentage of diel departures at (d) Polite, (e) Dividi and (f) Désiré in relation to the $24 \mathrm{~h}$ clock. Mean arrival and departure time ( $\pm 95 \%$ confidence interval [CI]) are superimposed. Grey error bars indicate unreliable CI due to low sample number or high spread of data; $r$ : length of mean vector; $\mathrm{n}$ : number of samples; $\mathrm{p}$ : probability of data being randomly distributed (Rayleigh test of randomness: $\alpha=0.05)_{i}{ }^{*}$ indicates significant difference 


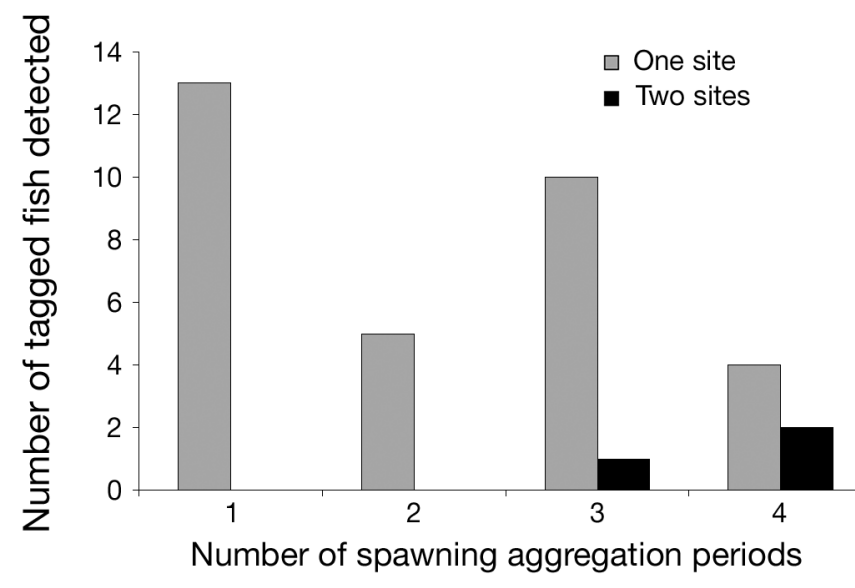

Fig. 6. Siganus sutor. The number of tagged fish detected $(n=35)$ at the monitored spawning aggregation sites against the number of spawning aggregation periods in which they were detected and the number of spawning aggregation sites at which detection of a tagged fish was made

$2011\left(4.1 \pm 0.7 \mathrm{~m}^{-2}\right)$ were 2 orders of magnitude higher than during observed periods when aggregations had not formed at that particular site $(\leq 0.03 \pm$ $0.01 \mathrm{~m}^{-2}$; Fig. 7a). Similarly, aggregation formation at Désiré was associated with large increases in mean fish density, with a 4.5-fold increase in February 2010 $\left(0.4 \pm 0.01 \mathrm{~m}^{-2}\right)$ compared to other observation periods $\left(\leq 0.09 \pm 0.1 \mathrm{~m}^{-2}\right.$; Fig. $\left.7 \mathrm{~b}\right)$.

\section{Turnover}

Combining data from Dividi on the residency times and density of fish over 2 spawning aggregation periods, it is apparent that the time fish resided at the aggregation site was less than the duration of the overall aggregation (Fig. 8). This is suggestive of turnover of fish (i.e. arrival of new spawners and departure of already spawned individuals) during the course of an aggregation. In January and March 2011, the mean residency time at Dividi was $0.6 \pm$ $0.7 \mathrm{~d}(\sim 14.4 \pm 16.8 \mathrm{~h}$; Fig. 8a) and $0.7 \pm 0.4 \mathrm{~d}(\sim 16.8 \pm$ 9.6 h; Fig 8b), respectively, while in both months, aggregations were present at the site over 3 consecutive days; even though the exact times of aggregation onset and termination are not known, the minimum aggregation duration was $48 \mathrm{~h}$. In January 2011, 9 of the 11 fish $(81.8 \%)$ left the site within $24 \mathrm{~h}$, whereas in March 20115 of the 6 fish (83.3\%) left the site within $24 \mathrm{~h}$. If the mean residency time is representative of all fish participating in these 2 aggregations, this would equate to aggregation turnover rates of 3.3 and 2.9 in January and March 2011, respectively.

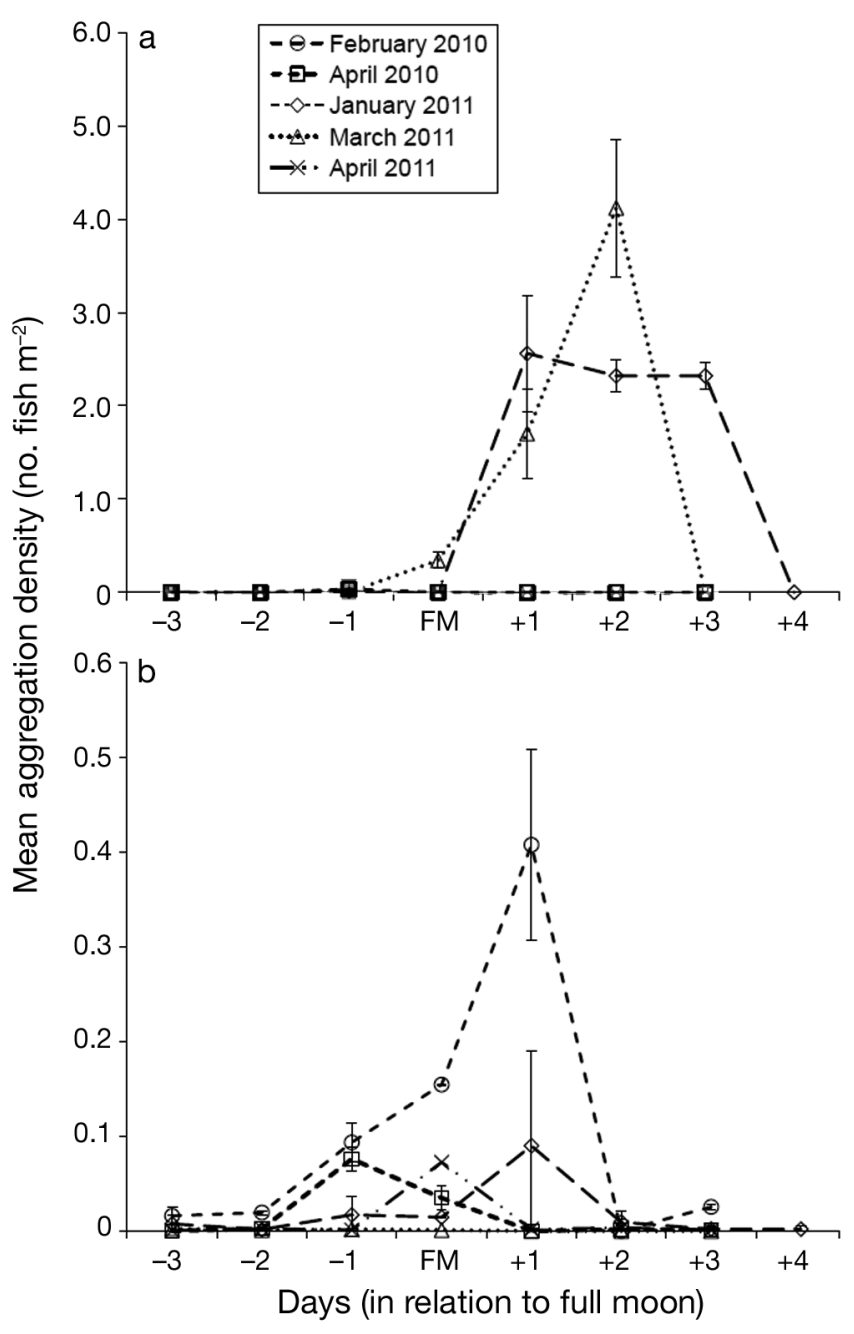

Fig. 7. Siganus sutor. Mean $( \pm \mathrm{SD})$ aggregation density (no. fish $\mathrm{m}^{-2}$ ) estimated from underwater visual census against days either side of the full moon (FM) at (a) Dividi and (b) Désiré in 5 different months of the spawning season in 2010 and 2011

\section{DISCUSSION}

The application of acoustic telemetry and UVC in this study has improved understanding of the spatial and temporal dynamics of commercially exploited Siganus sutor spawning aggregations that form close to the island of Praslin, Seychelles. A notable finding was the combination of short individual residency times relative to aggregation duration, leading to the demonstration of turnover and estimation of rates that would not have been possible with application of either UVC or acoustic tagging in isolation. Clearly, the use of multiple techniques is beneficial to the study of FSA dynamics. Though UVC was not undertaken in the first half of the spawning season, the 


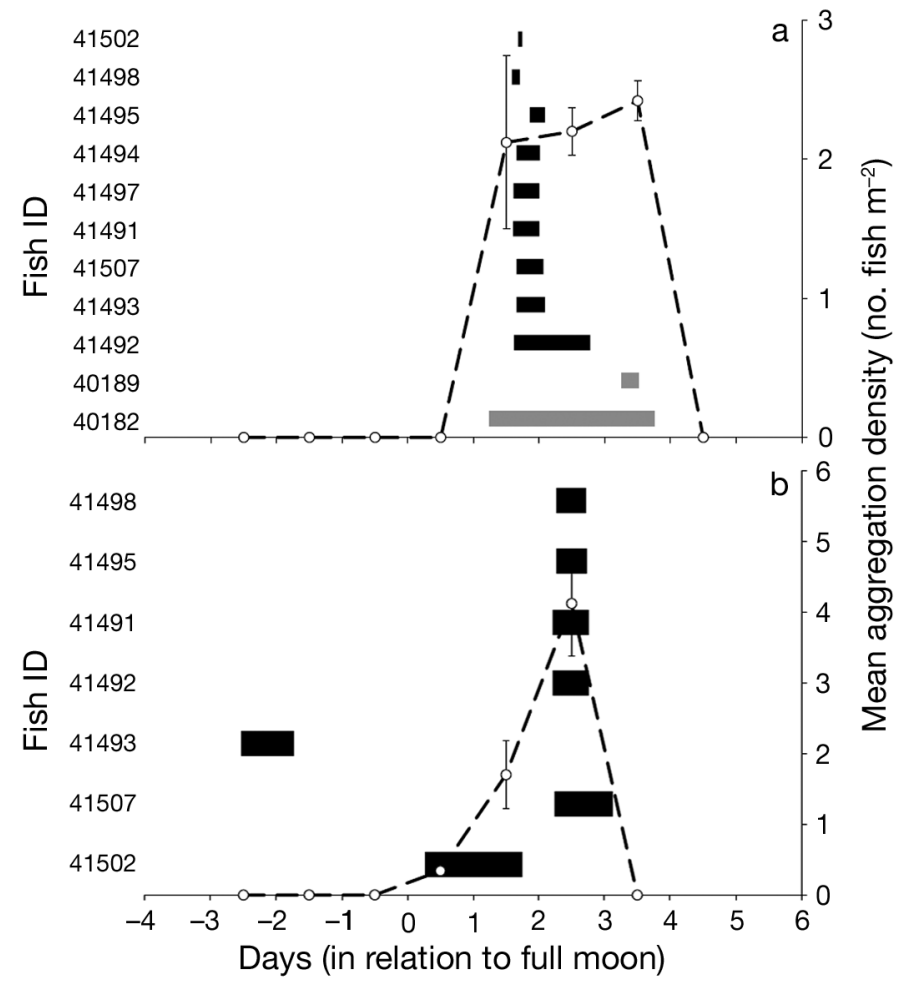

Fig. 8. Siganus sutor. Mean $( \pm \mathrm{SD})$ aggregation density (no. fish $\mathrm{m}^{-2}$ ) estimated from underwater visual census (line graph) and timing of detections of acoustically tagged fish (bar graph) at Dividi in (a) January and (b) March 2011. (Grey bars) Fish that were tagged in monitoring Period 1 and (black bars) fish that were tagged in monitoring Period 2

longer residency times recorded at FSA sites in the first monitoring period indicate that lower turnover rates will occur if aggregation duration remains constant across the spawning season. Turnover of FSAs has been reported for only a few species, notably the leopard coral trout Plectropomus leopardus (Zeller 1998) and the orange roughy Hoplostethus atlanticus (Bull et al. 2001). High turnover rates were to a large extent caused by arrivals and departures occurring throughout the duration of the aggregation. As some residency times were truncated the actual turnover rates could be less than calculated. More tagging and monitoring of $S$. sutor in spawning aggregations should help in refining turnover rates. Our novel finding is that the spawning aggregation dynamics of $S$. sutor could be fundamentally different from many other transient spawners, where there is a gradual build-up of spawning individuals and most departures occur very quickly after peak aggregation and spawning (Rhodes \& Sadovy 2002, Rhodes et al. 2012). Failure to account for turnover, should it occur, will result in underestimation of the number of fish that participate in spawning aggregations. Moreover, if spawning aggregations are to provide cost-effective means of monitoring adult population status, estimates of turnover rates will be critical.

Acoustic coverage of the 3 FSA sites was highly variable and precluded statistical comparisons of residency times between sites. However, as demonstrated for Polite, residency times vary with higher mean residency time in the first monitoring period, corresponding to the first half of the spawning aggregation season. A shortening of residency time may relate to changes in reproductive output if the energy budget tends towards increased somatic growth as the protracted spawning season progresses. Many species spawn multiple batches of eggs within a single aggregation (Hunter \& Macewicz 1980, Pears et al. 2007), including the closely related Siganus canaliculatus (Hoque et al. 1999), and co-occurrence of post-ovulatory follicles and hydrated oocytes has been observed in ovaries of $S$. sutor sampled from Praslin aggregations (Seychelles Fishing Authority unpubl. data). Detailed reproductive biology studies of batch size and the frequency of their release across the spawning season would offer insights into variation in residency times.

The findings of this study confirmed that Siganus sutor visit the Polite and Dividi aggregation sites mostly around the full moon, with the majority of arrivals and departures at these 2 sites occurring within the $7 \mathrm{~d}$ spawning aggregation period. Observations of running ripe individuals caught around the full moon at Dividi by Robinson et al. (2011) confirm that these aggregations are being formed for spawning and that spawning in this species is synchronised with the full moon. Fishers have reported a full moon spawning periodicity for populations of this species elsewhere in the western Indian Ocean (Samoilys et al. 2006).

Peaks in arrivals at dawn and departures at dusk for both Polite and Dividi suggest that fish are mostly migrating to and from the spawning aggregation sites at night or during crepuscular periods. Home range reefs, migration routes and times are yet to be documented, though fishers appear to monitor the build-up of small aggregations on near shore fringing reefs a day prior to shifting their fishing effort to the offshore aggregation sites (Robinson et al. 2011). However, at Polite, a few arrivals and departures also 
occurred in the middle of the day. A plausible explanation for differences in arrival and departures among sites stems from the acoustic coverage provided by the monitoring arrays. Acoustic coverage at Dividi and Désiré was high as the sites cover relatively small areas of 16000 and $2900 \mathrm{~m}^{2}$, respectively. Conversely, acoustic coverage of Polite was low, as the site is both comparatively large, covering an area of approximately $70000 \mathrm{~m}^{2}$, and complex, being comprised of many granite patch reefs (see Fig. 1). Consequently, exact timing of arrivals at and departures from Polite at dawn and dusk may not have been recorded. Alternatively, behavioural plasticity in preferred diel timing of migration from home reefs to FSA sites could exist in Siganus sutor. Plasticity of diel activity rhythm has been found in $S$. lineatus populations occurring in different habitats (Fox \& Bellwood 2011). At Désiré, the lunar and diel patterns of arrivals and departures were markedly different from those observed at the other 2 FSA sites. We believe that Désiré forms part of the home range of some of the fish that were tagged there and that most of the arrivals and departures that we recorded were related more to foraging than participation in spawning aggregations. This is supported by the fact that large number of detections of tagged fish at Désiré were made outside the spawning aggregation periods, as opposed to Polite and Dividi, where detections were mostly concentrated in the spawning periods. It could also be due to differential use of different areas in the large home ranges that at least 1 species from this genus is known to have (Fox \& Bellwood 2011). Crepuscular and night periods are generally associated with high rates of predation (Danilowicz \& Sale 1999, Holbrook \& Schmitt 2002, but see Sancho et al. 2000) and predation on spawning fish is known to be intense at some sites (Moyer 1987, Sancho et al. 2000). Therefore, the timing of arrivals and departures to crepuscular periods may be a strategy for reducing the encounter rate with predators at spawning aggregation sites.

Siganus sutor exhibited high spawning site fidelity during the 2 monitoring periods, which when combined, constituted almost the entire spawning season for the population (Robinson et al. 2011). Nonetheless, since fidelity was not absolute, a degree of behavioural polymorphism (Attwood \& Bennett 1994) appears to occur in the population. For polymorphic individuals, selecting spawning sites is unlikely to be a random process, as relatively high levels of intermonthly fidelity to a single site (up to 3 consecutive months) were still observed after or prior to changing sites. Our interpretation is that behavioural polymor- phism could actually be a bet-hedging strategy against environmental variability (Lambert \& Ware 1984) or a response to changes in mating opportunities (Draud \& Itzkowitz 2004) at a particular FSA site.

Variation in the number of detections between day and night may be explained by 3 factors. Firstly, most Siganus sutor arrived at the aggregation sites at dawn and departed at dusk, a pattern that served to concentrate the presence of tagged fish to daytime periods. Secondly, S. sutor appear to take refuge within the coral structures on fringing reefs at night (J. P. Bijoux pers. obs.), which would also contribute to a reduction in the number of diurnal detections if such behaviour occurs at spawning sites (Zeller 1997, Chateau \& Wantiez 2007). Thirdly, high levels of background noise at night compared to daytime levels (e.g. Bardyshev 2007) will result in a greater potential for distortion of tag signals and reduce night detections.

While several hypotheses have been postulated as to why fish select certain sites to spawn (Molloy et al. 2012), little in the way of consensus on underlying mechanisms has emerged from the existing empirical or theoretical evidence. In the case of the Siganus sutor population at Praslin, coastal geomorphology and physical characteristics appear to be important in the selection of spawning sites. All spawning sites studied are located offshore at depths of between 15 and $20 \mathrm{~m}$, with coral cover in excess of $60 \%$ and a moderate current speed of between 0.1 and $0.3 \mathrm{~m} \mathrm{~s}^{-1}$ (Seychelles Fishing Authority unpubl. data). Since siganids have negatively buoyant, demersal and adhesive eggs (Thresher 1991), they presumably require a clean surface for egg attachment (e.g. Gafny et al. 1992), conditions that may be met on the offshore granite patch reefs selected by $S$. sutor at Praslin, as opposed to inshore reefs that receive comparatively high levels of terrigenous sediment and run-off (Littler et al. 1991). Compared to emergent fringing reefs, submerged offshore sites may also prevent eggs from being dislodged by wave action. Similarly, in Kenya, S. sutor are known to spawn on offshore patch reefs deeper than $15 \mathrm{~m}$ (M. Samoilys pers. comm.), while spawning at similar depths has been documented in $S$. lineatus from Micronesia (Johannes 1981).

This study provided information on the spatial and temporal spawning aggregation dynamics of a commercially important species of Siganidae, a family for which reproductive behaviour is poorly documented compared to families such as the Serranidae. In the western Indian Ocean, Siganus sutor constitutes the most important target species in many coastal reef 
fisheries (Hicks \& McClanahan 2012) and, as dominant herbivores, siganids are key species for coral reef resilience (Cheal et al. 2010). In addition to gear management, spatial measures are often advocated and applied for fisheries management in the region, increasingly in the context of co-management of locally managed marine areas that often include small-scale closures (Cinner et al. 2012). However, the efficacy of management and conservation for S. sutor will depend, to a large extent, on designing measures that address the many complex spatial and temporal dynamics demonstrated here, including the use of offshore sites for spawning, partial infidelity to spawning sites, and turnover within aggregations. It is imperative that the behaviour of target species is understood and used to guide management (Semmens et al. 2010, Rhodes et al. 2012).

Acknowledgements. This work was supported through grants from the Marine and Coastal Science for Management (MASMA) program (Grant No. MASMA/OR/2008/06) of the Western Indian Ocean Marine Science Association (WIOMSA) and from the Global Environmental Facility (GEF) Small Grant Program (SGP) to the Praslin Fishers Association (PFA) (Grant No. SEY/SGP/OP4/Y3/RAF/2010/ 05). Financial and logistical support was also provided by the Seychelles Fishing Authority (SFA) through the European Union (EU) from the sectoral policy support funds of the EU/Seychelles Fisheries Protocols under the Fisheries Partnership Agreement. We thank the members of the PFA for support in catching fish and the research technicians of the SFA and crew of RV 'L'Amitié' for technical and logistical assistance. C. Gerry is thanked for help with the production of maps and side-scan sonar data collection and analysis. This publication was made possible through support provided by the Institut de Recherche pour le Développement Département Soutien et Formation des communautés scientifiques du Sud (IRD-DSF). The comments of 4 anonymous reviewers improved the manuscript.

\section{LITERATURE CITED}

Aguilar-Perera A (2006) Disappearance of a Nassau grouper spawning aggregation off the southern Mexican Caribbean coast. Mar Ecol Prog Ser 327:289-296

> Aguilar-Perera A, Aguilar-Dávila W (1996) A spawning aggregation of Nassau grouper Epinephelus striatus (Pisces: Serranidae) in the Mexican Caribbean. Environ Biol Fishes 45:351-361

> Attwood CG, Bennett BA (1994) Variation in dispersal of galjoen (Coracinus capensis) (Teleostei: Coracinidae) from a marine reserve. Can J Fish Aquat Sci 51:1247-1257

Bardyshev V (2007) Underwater ambient noise in shallowwater areas of the Indian Ocean within the tropical zone. Acoust Phys 53:167-171

Batschelet E (1981) Circular statistics in biology. Academic Press, London

> Beets J, Friedlander A (1999) Evaluation of a conservation strategy: a spawning aggregation closure for red hind,
Epinephelus guttatus, in the U.S. Virgin Islands. Environ Biol Fishes 55:91-98

Bull B, Doonan I, Tracey D, Hart A (2001) Diel variation in spawning orange roughy (Hoplostethus atlanticus, Trachichthyidae) abundance over a seamount feature on the north-west Chatham Rise. NZ J Mar Freshw Res 35: 435-444

Chateau O, Wantiez L (2007) Site fidelity and activity patterns of a humphead wrasse, Cheilinus undulatus (Labridae), as determined by acoustic telemetry. Environ Biol Fishes 80:503-508

> Cheal A, MacNeil M, Cripps E, Emslie M, Jonker M, Schaffelke B, Sweatman H (2010) Coral-macroalgal phase shifts or reef resilience: links with diversity and functional roles of herbivorous fishes on the Great Barrier Reef. Coral Reefs 29:1005-1015

Choat JH (2012) Spawning aggregations in reef fishes; ecological and evolutionary processes. In: Sadovy de Mitcheson Y, Colin PL (eds) Reef fish spawning aggregations: biology, research and management. Springer, Heidelberg, p 85-116

> Cinner JE, McClanahan TR, MacNeil MA, Graham NAJ and others (2012) Comanagement of coral reef social-ecological systems. Proc Natl Acad Sci USA 109:5219-5222

Cox DR (1972) Regression models and life-tables. J R Stat Soc B 34:187-220

> Danilowicz BS, Sale PF (1999) Relative intensity of predation on the French grunt, Haemulon flavolineatum, during diurnal, dusk, and nocturnal periods on a coral reef. Mar Biol 133:337-343

Domeier ML (2012) Revisiting spawning aggregations: definitions and challenges. In: Sadovy de Mitcheson Y, Colin PL (eds) Reef fish spawning aggregations: biology, research and management. Springer, Heidelberg, p 1-20

Domeier ML, Colin PL (1997) Tropical reef fish spawning aggregations: defined and reviewed. Bull Mar Sci 60: 698-726

> Draud MJ, Itzkowitz M (2004) Mate numbers or mate quality: female mate choice in the polygynandrous variegated pupfish (Cyprinodon variegatus). Ethol Ecol Evol 16:1-13

Fox RJ, Bellwood DR (2011) Unconstrained by the clock? Plasticity of diel activity rhythm in a tropical reef fish, Siganus lineatus. Funct Ecol 25:1096-1105

Gafny S, Gasith A, Goren M (1992) Effect of water level fluctuation on shore spawning of Mirogrex terraesanctae (Steinitz), (Cyprinidae) in Lake Kinneret, Israel. J Fish Biol 41:863-871

> Govinden R, Jauhary R, Filmalter J, Forget F, Soria M, Adam S, Dagorn L (2012) Movement behaviour of skipjack (Katsuwonus pelamis) and yellowfin (Thunnus albacares) tuna at anchored fish aggregating devices (FADs) in the Maldives, investigated by acoustic telemetry. Aquat Living Resour, doi:10.1051/alr/2012022

Grandcourt EM, Cesar HSJ (2003) The bio-economic impact of mass coral mortality on the coastal reef fisheries of the Seychelles. Fish Res 60:539-550

Heupel MR, Semmens JM, Hobday AJ (2006) Automated acoustic tracking of aquatic animals: scales, design and deployment of listening station arrays. Mar Freshw Res 57:1-13

> Hicks CC, McClanahan TR (2012) Assessing gear modifications needed to optimize yields in a heavily exploited, multi-species, seagrass and coral reef fishery. PLoS ONE $7: \mathrm{e} 36022$

Holbrook SJ, Schmitt RJ (2002) Competition for shelter 
space causes density-dependent predation mortality in damselfishes. Ecology 83:2855-2868

Hoque MM, Takemura A, Matsuyama M, Matsuura S, Takano K (1999) Lunar spawning in Siganus canaliculatus. J Fish Biol 55:1213-1222

Hornell J (1927) Report on the fisheries and fish resources of the Seychelles Islands. H.M.S.O., London

Hunter JR, Macewicz BJ (1980) Sexual maturity, batch fecundity, spawning frequency, and temporal pattern of spawning for the Northern anchovy, Engraulis mordax, during the 1979 spawning season. Calif Coop Ocean Fish Invest Rep 21:139-149

Johannes RE (1981) Words of the lagoon: Fishing and marine lore in the Palau District of Micronesia. University of California Press, Berkley, CA

Johannes RE, Squire L, Graham T, Sadovy Y, Renguul H (1999) Spawning aggregations of groupers (Serranidae) in Palau. The Nature Conservancy Marine Research Series Publication No. 1, The Nature Conservancy, Arlington

Kamukuru AT (2009) Trap fishery and reproductive biology of the whitespotted rabbitfish Siganus sutor (Siganidae), within the Dar es Salaam Marine Reserves, Tanzania. W Indian Ocean J Mar Sci 8:75-86

Kaunda-Arara B, Rose GA, Muchiri S, Kaka R (2003) Longterm trends in coral reef fish yields and exploitation rates of commercial species from coastal Kenya. W Indian Ocean J Mar Sci 2:105-116

- Lambert TC, Ware DM (1984) Reproductive strategies of demersal and pelagic spawning fish. Can J Fish Aquat Sci 41:1565-1569

Littler MM, Littler DS, Titlyanov EA (1991) Comparisons of $\mathrm{N}$ - and P-limited productivity between high granitic islands versus low carbonate atolls in the Seychelles Archipelago: a test of the relative-dominance paradigm. Coral Reefs 10:199-209

Molloy PP, Côté IM, Reynolds JD (2012) Why spawn in aggregations? In: Sadovy de Mitcheson Y, Colin PL (eds) Reef fish spawning aggregations: biology, research and management. Springer, Heidelberg, p 57-84

Moyer JT (1987) Quantitative observations of predation during spawning rushes of the labrid fish Thalassoma cupido at Miyake-jima, Japan. Jpn J Ichthyol 34:76-81

Ohta I, Kakuma S (2005) Periodic behavior and residence time of yellowfin and bigeye tuna associated with fish aggregating devices around Okinawa Islands, as identified with automated listening stations. Mar Biol 146: 581-594

> Pears RJ, Choat JH, Mapstone BD, Begg GA (2006) Demography of a large grouper, Epinephelus fuscoguttatus, from Australia's Great Barrier Reef: implications for fishery management. Mar Ecol Prog Ser 307:259-272

Pears RJ, Choat JH, Mapstone BD, Begg GA (2007) Reproductive biology of a large, aggregation-spawning serranid, Epinephelus fuscoguttatus (Forsskål): management implications. J Fish Biol 71:795-817

$>$ Rhodes KL, Sadovy Y (2002) Temporal and spatial trends in spawning aggregations of camouflage grouper, Epinephelus polyphekadion, in Pohnpei, Micronesia. Environ Biol Fishes 63:27-39

Rhodes KL, Tupper MH (2008) The vulnerability of reproductively active squaretail coralgrouper (Plectropomus areolatus) to fishing, based on acoustic and conventional tagging surveys in Pohnpei, Micronesia. Fish Bull 106: 194-203

Rhodes KL, McIlwain J, Joseph E, Nemeth RS (2012) Repro- ductive movement, residency and fisheries vulnerability of brown-marbled grouper, Epinephelus fuscoguttatus (Forskkål, 1775). Coral Reefs 31:443-453

Robert M, Dagorn L, Deneubourg J, Itano D, Holland K (2012) Size-dependent behavior of tuna in an array of fish aggregating devices (FADs). Mar Biol 159:907-914

$>$ Robichaud D, Rose GA (2003) Sex differences in cod residency on a spawning ground. Fish Res 60:33-43

Robinson J, Isidore M, Marguerite MA, Öhman MC, Payet RJ (2004) Spatial and temporal distribution of reef fish spawning aggregations in the Seychelles-An interview-based survey of artisanal fishers. W Indian Ocean J Mar Sci 3:63-69

Robinson J, Samoilys MA, Grandcourt E, Julie D, Cedras M, Gerry C (2011) The importance of targeted spawning aggregation fishing to the management of Seychelles' trap fishery. Fish Res 112:96-103

Sadovy YJ (1996) Reproduction of reef fishery species. In: Polunin NVC, Roberts C (eds) Reef fisheries. Chapman \& Hall, London, p 15-59

Sadovy Y, Domeier M (2005) Are aggregation-fisheries sustainable? Reef fish fisheries as a case study. Coral Reefs 24:254-262

Sadovy de Mitcheson Y, Colin PL (eds) (2012) Conclusion. In: Reef fish spawning aggregations: biology, research and management. Springer, Heidelberg, p 566-584

Sala E, Ballesteros E, Starr RM (2001) Rapid decline of Nassau grouper spawning aggregations in Belize: fishery management and conservation needs. Fish Bull 26: 23-30

Samoilys MA, Squire L (1994) Preliminary observations on the spawning behavior of coral trout, Plectropomus leopardus (Pisces: Serranidae). Bull Mar Sci 54:332-342

Samoilys MA, Church J, Kaunda-Arara B, Kamukuru A, Jiddawi N (2006) Preliminary findings on spawning aggregations of reef fishes in East Africa. Proc 10th Int Coral Reef Symp, Okinawa 1:1335-1346

Sancho G, Petersen CW, Lobel PS (2000) Predator-prey relations at a spawning aggregation site of coral reef fishes. Mar Ecol Prog Ser 203:275-288

Semmens JM, Buxton CD, Forbes E, Phelan MJ (2010) Spatial and temporal use of spawning aggregation sites by the tropical sciaenid Protonibea diacanthus. Mar Ecol Prog Ser 403:193-203

> Shapiro DY, Sadovy Y, McGehee MA (1993) Size, composition, and spatial structure of the annual spawning aggregation of the red hind, Epinephelus guttatus (Pisces: Serranidae). Copeia 1993:399-406

Starr RM, Sala E, Ballesteros E, Zabala M (2007) Spatial dynamics of the Nassau grouper Epinephelus striatus in a Caribbean atoll. Mar Ecol Prog Ser 343:239-249

Thresher RE (1991) Geographic variability in the ecology of coral reef fishes: evidence, evolution and possible implications. In: Sale PF (ed) The ecology of fishes on coral reefs. Academic Press, San Diego, p 401-436

Woodland DJ (1990) Revision of the fish family Siganidae with descriptions of two new species and comments on distribution and biology. Indo-Pac Fish 19:1-136

Zeller DC (1997) Home range and activity patterns of the coral trout Plectropomus leopardus (Serranidae). Mar Ecol Prog Ser 154:65-77

Zeller DC (1998) Spawning aggregations: patterns of movement of the coral trout Plectropomus leopardus (Serranidae) as determined by ultrasonic telemetry. Mar Ecol Prog Ser 162:253-263 


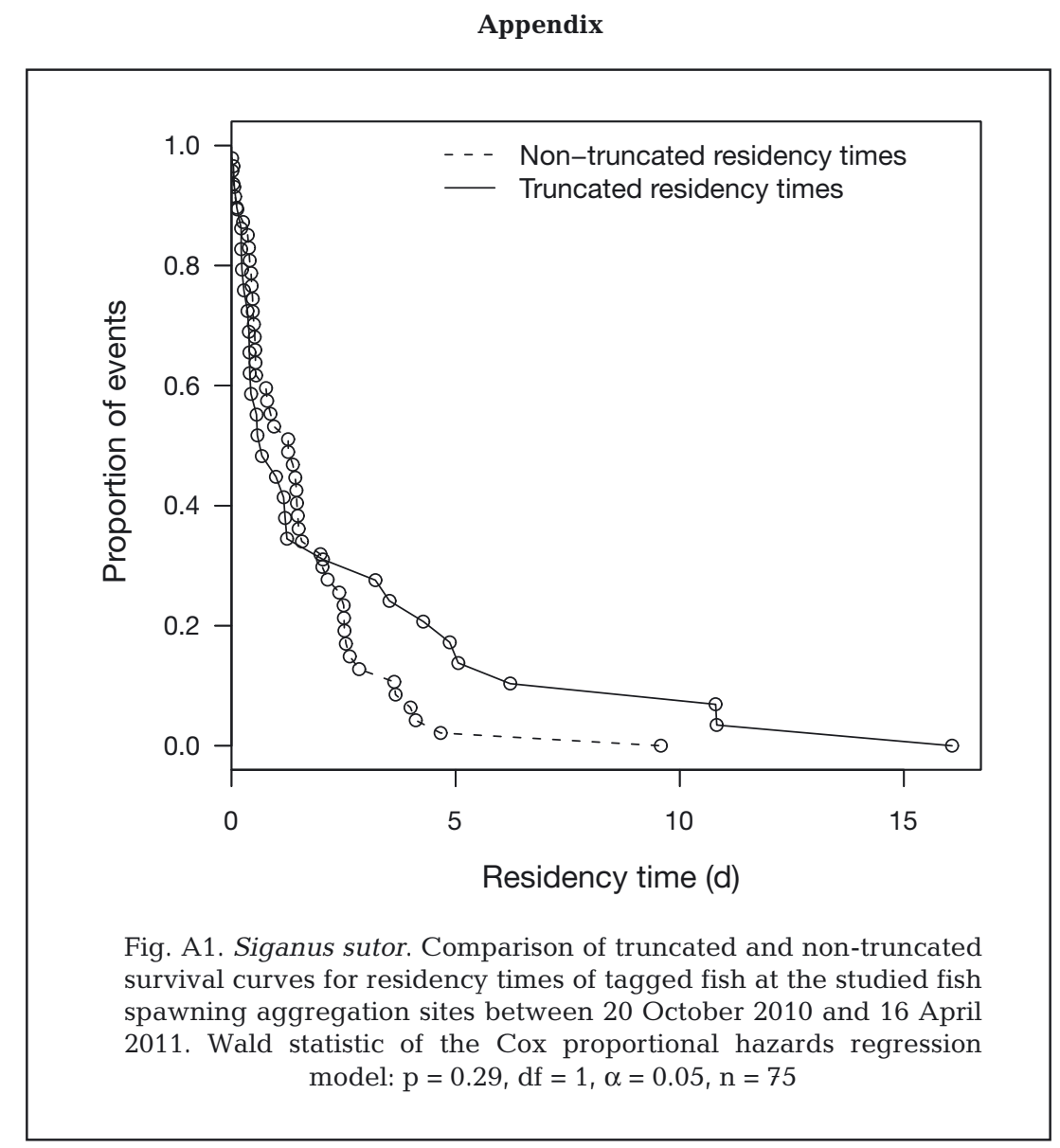

Editorial responsibility: Hans Heinrich Janssen, Oldendorf/Luhe, Germany
Submitted: May 22, 2012; Accepted: October 11, 2012

Proofs received from author(s): February 1, 2013 